\section{Long-term cannabis use and mental health}

\author{
WAYNE HALL and NADIA SOLOWIJ
}

The mental health consequences of the daily or near-daily use of cannabis over years and decades remain uncertain, and are likely to remain so for some time given the difficulties involved in investigating them. Nevertheless, there is sufficient evidence that its effects are neither as benign as proponents of its legalisation often argue, nor as malign as some partisans of continued prohibition claim (Hall et al, 1994).

\section{DEPENDENCE}

Dependence on cannabis is the most prevalent and under-appreciated risk of regular cannabis use. About $10 \%$ of those who ever use cannabis (Anthony et al, 1994) and onethird to one-half of those who use it daily (Kandel \& Davies, 1992) will lose control of their cannabis use and continue to use the drug in the face of problems they believe are caused or exacerbated by its use. Animal studies show that there is a cannabis withdrawal syndrome (Compton et al, 1990) but withdrawal symptoms are not often reported by cannabis users, probably because they are generally mild and not recognised as such. Uncertainty remains as to how difficult it is to overcome cannabis dependence and what is the best way to assist individuals to become abstinent (Hall et al, 1994).

\section{ADOLESCENT DEVELOPMENT}

The effects of cannabis use on adolescent development are a major community concern (Kandel \& Davies, 1992). The apparent severity of its adverse effects on adolescent development has been exaggerated because it is the most troubled adolescents who are the heaviest cannabis users (Hall et al, 1994; Fergusson \& Horwood, 1997). None the less, there is now evidence from longitudinal studies (Hall et al, 1994; Fergusson et al, 1996) that regular cannabis use independently contributes to poor psy- chosocial outcomes among adolescents and young adults.

A more contentious matter has been whether cannabis use increases the likelihood that adolescents will use other illicit drugs. Among American adolescents in the 1970s (Kandel \& Davies, 1992) the use of alcohol and tobacco typically preceded the use of cannabis, which in turn preceded the use of hallucinogens and 'pills', and in a minority, the use of heroin and cocaine. The earlier the age at which cannabis was first used, and the greater the involvement with it, the more likely an adolescent was to use heroin and cocaine (Kandel \& Davies, 1992).

The least likely explanation of the role played by cannabis in this sequence of drug involvement is that the pharmacological effects of cannabis directly increase the use of other drugs. A more plausible explanation is that the sequence reflects two processes: the greater recruitment to early cannabis use of nonconforming adolescents who have a propensity to use all types of illicit drugs; and their socialisation within an illicit drug-using peer group that provides the opportunity and encouragement to use other illicit drugs (Hall et al, 1994).

\section{COGNITIVE IMPAIRMENT}

The possibility that chronic cannabis use causes cognitive impairment has been extensively investigated but much of this research has been poorly controlled (Hall et al, 1994). Long-term heavy cannabis users do not show the marked cognitive impairment found in chronic alcoholics (Hall et al, 1994) but the cognitive performance of chronic and heavy cannabis users is poorer than that of nonusers on tasks of selective and focused attention, visual and verbal memory and visuo-motor functions (Solowij et al, 1995; Pope \& Yurgelun-Todd, 1996). The personal and social significance of these findings, and the degree to which they can be reversed by abstinence, remain to be determined.

\section{PSYCHOSIS}

The impact of chronic cannabis use on the incidence and severity of schizophrenic symptoms has become an understandable concern because of increasing cannabis use among patients with schizophrenia in some countries (Hall et al, 1994). There was also an impressive association between cannabis use and the incidence of schizophrenia in a longitudinal study of 50000 Swedish male conscripts (Andreasson et al, 1987). This study found that the risk of receiving a diagnosis of schizophrenia over the next 15 years increased linearly with the number of times that an individual had used cannabis by the age of 18 (Andreasson et al, 1987). There is still argument about the significance of this finding (Thornicroft, 1990). It is probable that cannabis use precipitates schizophrenia in the vulnerable and exacerbates symptoms in affected individuals who continue to use it (Negrete et al, 1986). It is less likely that cannabis use can precipitate schizophrenic illness that would not otherwise have occurred, because the incidence of schizophrenia has not increased in countries such as Australia, which have had dramatic increases in the prevalence of adolescent cannabis use over the past two decades (Hall et al, 1994).

Two putative effects of cannabis use on mental health can be briefly mentioned. First, heavy cannabis use can affect motivation but there is no need to invoke an 'amotivational syndrome' to explain the narrowed interests, loss of motivation and reduced achievement seen in some chronic heavy cannabis users; these are symptoms of chronic cannabis intoxication (Hall et al, 1994). Second, an early report of structural brain damage in chronic cannabis users (Campbell et al, 1971) has not been borne out by better controlled studies using more sophisticated methods of investigation (Hall et al, 1994). Chronic cannabis use is unlikely to cause gross structural brain damage because it acts on a specific receptor. One cannot rule out the possibility that prolonged heavy cannabis use may affect the receptor in ways that affect brain function.

\section{REFERENCES}

Andreasson, S., Allebeck, P., Engstrom, A., ef al (1987) Cannabis and schizophrenia: A longitudinal study of Swedish conscripts. Lancet, ii. 1483-1486.

Anthomy, J. C., Warner, L. A. \& Kessler, R. C. (1994) Comparative epidemiology of dependence on tobacco. alcohol, controlled substances and inhalants: basic findings from the National Comorbidity Study. Clinical and Experimental Psychopharmacology, 2. 244-268. 
Campbell, A. M. G., Evans, M., Thomson, J. L. G., et al (1971) Cerebral atrophy in young cannabis smokers. Loncet. ". 1219-1224.

Compton, D. R., Dewey, W. L. \& Martin, B. R. (1990) Cannabis dependence and tolerance production. Advances in Alcohol and Substance Abuse, 9. 128-147.

Ferzusson, D. M. \& Hormood, L. J. (1997) Early onset cannabis use and psychosocial adjustment in young adults. Addiction. 92. 279-296.

_, Lynskey, M. T. Horwood, L. J. (1996) The short-term consequences of early onset cannabis use. Journal of Abnormal Child Psychology, 24, 499-512.

Hall, W., Solowij, N. Lemon, J. (1994) Heolth and Psychological Consequences of Cannabis Use. National Drug Strategy Monograph Series No. 25. Canberra: Australian Government Publication Service.

Kandel, D. B. Davies, M. (1992) Progression to regular marijuana involvement: Phenomenology and risk factors for near daily use. In Vulnerability to Drug Abuse (eds M. Glanz \& R.

WAYNE HALL, PhD, NADIA SOLOWIJ. PhD, National Drug and Alcohol Research Centre, University of New South Wales, Sydney, Australia

Correspondence: Professor Wayne Hall, National Drug and Alcohol Research Centre. University of New South Wales. Sydney. NSW 2052. Australia

(First received 7 October 1996, revised 30 January 1997, accepted 7 February 1997)

Pickens). pp. 211-253. Washington. DC: American Psychological Association

Negrete, J. C., Knapp, W. P., Douglas, D., et al (1986)

Cannabis affects the severity of schizophrenic symptoms: results of a clinical survey. Psychological Medicine, 16, 515-520.

Pope, H. G. \& Yurgelun-Todd, D. (1996) The residual cognitive effects of heavy marijuana use in college students. Journal of the American Medical Association, 275, 521-527.
Solowi), N., Michie, P. T. \& Fox, A. M. (1995) Differential impairments of selective attention due to frequency and duration of cannabis use. Biological Psychiatry, 37. 731-739.

Thornicroft, G. (1990) Cannabis and psychosis. Is there epidemiological evidence for an association? British journol of Psychiatry, 157. 25-33. 